\title{
Choroidal and Ciliary Body Melanoma pT2a TNM Finding v8
}

National Cancer Institute

\section{Source}

National Cancer Institute. Choroidal and Ciliary Body Melanoma pT2a TNM Finding v8. NCl Thesaurus. Code C140637.

Choroidal and ciliary body melanoma, tumor size category 2 without ciliary body involvement and extraocular extension. (from AJCC 8th Ed.) 